\title{
Effects of Transplanting Time and Vinyl-film Mulching Treatment on the Biomass Production of Artemisia annua L. in the Saemangeum Reclaimed Tidal Lands in Korea
}

\author{
Jae-Do Song, Yong-Man Sohn, Myung-Hi Lee ${ }^{1}$, Geon-Yeong Jeon, Doo-Hwan Kim, and Moo-Eon Park* \\ Rural Research Institute. KARICO. Ansan 426-170, Korea, ${ }^{1}$ KRFI-Korea, Seoul 157-27.
}

\begin{abstract}
The experiment was caried out to find the effects of transplanting time and vinyl-film mulching treatment on the growth of artemisia by randomized block design with three replications. The experiment site $(100 \times 130 \mathrm{~m})$ was temporally established in the south-eastem part of Saemangeum reclaimed tidal land (near Gwanghwal myun, Gimjae-gun, Jellabukdo). Artemisia plants had been partly suffered from salt injury, because soil salinities in some area during growing period had been measured higher than $10 \mathrm{dS} \mathrm{m}^{-1}$. Growth of plant height and survival ratio of transplanted plants had been significantly correlated with soil salinity and then the regression equations between plant height $(y)$ and soil EC (x) and between survival ratio (y) and soil EC (x) were expressed as $y=-16.59 \ln (x)+43.852$ and $y=0.6453 x^{2}-17.566 x+103.99$, respectively. It was concluded that early transplanting and vinyl mulching was more beneficial for biomass production of artemisia, because biomass was 6.41 times more in the early transplanting than in the late transplanting, and 2.63 times more in the vinyl-film mulching than in the no mulching treatment.
\end{abstract}

Key words: Reclaimed tidal land, Artemisia annua L., Transplanting time. Vinyl-film mulching, Soil salinity

\section{Introduction}

Although the reclaimed tidal land has been traditionally used for agricultural purpose during the period of food shortage before the 2000's, the land-use plan of the Saemangeum reclaimed land will greatly share more with non-agricultural purpose than agricultural purpose by national development plan. Further more, the land use for agricultural purpose of the reclaimed land was also emphasized to be used for cultivation of cash crops instead of rice (Yoo \& Park, 2004: RRI, 2006). For development of bio industry, mass production of the potential crops as raw materials for medicinal or health products is very important to cope with mass consumption. In this regard, RDA (2007) carried out the research project about development of plant industry in the reclaimed land.

Artemisia has been widely used for herbal tea, drug and therapy because artemisinin as one of very important vital substances contained in artemisia plant acts as antimalarial activity (Jansen, 2006; Cumming, et al.,1997; Hou,

\footnotetext{
Received : January 19. 2011 Accepted : February 21. 2011

*Corresponding author : Phone: +82312558545

E-mail: parkmekr43@naver.com
}

2008; White, 1997; Koning, 2007). Although it was reported that some kinds of malaria have resistant to artemisinin (Noedl, et al., 2008; Dondorp, et al., 2009), artemisinin and its derivatives are still powerful drug for antimalaria in Africa and Asia and will be more intensively studied for utilization as allelochemical herbicide, anti-cancer and anti-parasite (Hou, 2008; White, 1997; Koning, 2007). For development of medicinal products, mass production of biomass is more important for effective substance to be extracted from artemisia plant.

For development of cultural techniques for mass production of artemisia, many detailed cultural techniques such as transplanting time, spacing of planting, fertilization, disease and insect control, variety and others should be studied (Ryu and Kim. 2006). However, there are no references for cultivation of artemisia except for searching agronomic characteristics of artemisia (Lee, 2010b). First of all, adaptability to soil salinity should be urgently studied for cultivation of artemisia in the Saemangeum reclaimed tidal land, because crops are generally very sensible to soil salinity (Knott. 1962). In addition, weed control is one of the most important problems because many kinds of weeds were found in the reclaimed land (NICS, 2006). Among various environmentally friendly 
cultural methods for weed control, mulching is one of the most popular method for weed control (Brady, 1990). And also transplanting time is another important thing to be studied urgently, because seeding time deeply related with cultural environmental conditions such as soil moisture, temperature, rainfall, etc (Ryu and Kim. 2006).

The objective of this research was studied in order for adaptability of artemisia to the reclaimed saline soil to be tested and for the effects of transplanting time and vinyl mulching treatment on growth of artemisia to be evaluated in the Saemangeum reclaimed tidal land.

\section{Materials and method}

Soil sampling and analysis Soil samples for soil physical analysis were collected from soil depth 0-20 and $20-40 \mathrm{~cm}$ before experiment in the experiment site $(100 \mathrm{x}$ $130 \mathrm{~m}$ ) where temporally established in the south-eastern part of Saemangeum reclaimed tidal land as shown in Fig. 1. (near Gwanghwal myun, Gimjae-gun, Jellabukdo). Soil texture was decided by USDA texture triangle according to particle size distribution data analyzed by pipeting method. Soil moisture holding capacity was measures for field capacity by pressure porous plate chamber method and for wilting point by membrane method (NAAS 2000). Soil water content was measured by gravimetric method for samples taken approximately biweekly from $0-20 \mathrm{~cm}$ in depth during growing period of artemisia.

Table 1 is the physical properties of soils before crop cultivation at the experiment site of the Saemangeum reclaimed land.

Composite soil samples for chemical analysis were collected and mixed together from surface soils of several places across the experiment site before and after crop cultivation. Soil chemical properties was analysed by standard method of the Rural Development Administrate (NAAS, 2000). Soil $\mathrm{pH}$ was measured with 1:5 (soil:water) ratio by $\mathrm{pH}$ meter. Various analysing methods for other chemical properties were used, such as Tyurin method for soil organic content, Lancaster method for available phosphate, $1 \mathrm{~N}-\mathrm{NH}_{4} \mathrm{OAc}(\mathrm{pH} 7.0)$ method for exchangeable cations. Soil EC of soil samples was measured with 1:5 (soil:water) by EC-meter for samples taken approximately biweekly from 0-20, 20-40 and 40-60 cm in depth during growing period of artemisia (NAAS, 2000). In fact, electrical conductivity of the saturated pastes (ECe) was highly significantly correlated with EC (1:5) and dilution factor (DF) should be differently applied according to soil texture when $\mathrm{ECe}$ was estimated from the values of $\mathrm{EC}_{1: 5}$ by dilution method, (Jung et al., 2000) and DF mainly depended on silt content of soil (Lee et al., 2003). However, soil EC was practically expressed as the values multiplied by five times of the values obtained from the 1:5 dilution method in this paper, because it was considered that measurement of reliable DF was complicate and time consuming works and spatial difference of silt content in a small field was also seriously enough to bring some errors (Park and Yoo, 1989). Spatial distribution map of soil salinity was obtained from $2 \times 2$ m data set

Table 1. Soil physical properties of the experimented soils before crop cultivation at the experiment site of the Saemangeum reclaimed land.

\begin{tabular}{|c|c|c|c|c|c|c|}
\hline \multirow{2}{*}{ Depth } & \multicolumn{3}{|c|}{ Particle distribution } & \multirow{2}{*}{$\begin{array}{c}\text { Soil } \\
\text { texture }\end{array}$} & \multicolumn{2}{|c|}{ Soil moisture } \\
\hline & Sand & Silt & Clay & & $\mathrm{FC}^{\dagger}$ & $\mathrm{WM}^{3}$ \\
\hline $\mathrm{cm}$ & \multicolumn{3}{|c|}{--------------------- \% --------------------- } & & 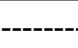 & - \\
\hline $0-20$ & 76.0 & 23.2 & 0.8 & LS & 15.9 & 4.8 \\
\hline $20-40$ & 80.7 & 18.8 & 0.5 & LS & 14.9 & 4.0 \\
\hline
\end{tabular}

${ }^{\dagger}$ FC: Field moisture capacity, ${ }^{\ddagger} \mathrm{WM}$; Wilting moisture

Table 2. Soil chemical properties before and after crop cultivation at the experiment site of the Saemangeum reclaimed land.

\begin{tabular}{|c|c|c|c|c|c|c|c|c|}
\hline \multirow{2}{*}{ Samples } & \multirow{2}{*}{$\mathrm{pH}$} & \multirow{2}{*}{ EC1:5 } & \multirow{2}{*}{$\mathrm{OM}$} & \multirow{2}{*}{ Av. $\mathrm{P}_{2} \mathrm{O}_{5}$} & \multicolumn{4}{|c|}{ Exchangeable cations } \\
\hline & & & & & $\mathrm{Ca}$ & $\mathrm{Mg}$ & $\mathrm{K}$ & $\mathrm{Na}$ \\
\hline & $1: 5$ & $\mathrm{dS} \mathrm{m}^{-1}$ & $\mathrm{~g} \mathrm{~kg}^{-1}$ & $\mathrm{mg} \mathrm{kg}^{-1}$ & \multicolumn{4}{|c|}{----- } \\
\hline Before cultivation & 8.4 & 1.9 & 2.0 & 33 & 0.7 & 1.8 & 0.68 & 3.22 \\
\hline After cultivation & 8.2 & 0.9 & 1.9 & 42 & 08 & 1.7 & 0.61 & 2.02 \\
\hline
\end{tabular}


interpolated from soil EC measurements of 28 positions by Punctual kriging (Davis, 1973).

Table 2 shows soil chemical properties of the experiment soils before and after crop cultivation at the experiment site of the Saemangeum reclaimed land.

Cultivation method and measurement of growth and biomass production. For the experiment, artemisia seedlings raised for 20-days in plastic pots were transplanted on the ridges of $90 \mathrm{~cm}$ intervals by $40 \times 50 \mathrm{~cm}$ spacing at the 17th of May and 1st of June in 2010. In order to estimate the effect of mulching treatment on the growth of artemisia, half area of the experimented parts transplanted on the 1st of July was mulched by black-vinyl film on the ridge. Amount of applied fertilizer was $12.6 \mathrm{~kg} 10^{-1}$ for N, $4.2 \mathrm{~kg} 10^{-1}$ for $\mathrm{P}_{2} \mathrm{O}_{5}$ and $7.2 \mathrm{~kg} 10^{-1}$ for $\mathrm{K}_{2} \mathrm{O}$ as basal dressing. and was $4 \mathrm{~kg} 10^{-1}$ for $\mathrm{N}$ as additional dressing. $600 \mathrm{~kg} 10^{-1}$ of compost made by mixtures of saw dust $27 \%$, charcoal 3\% and swine dung 27\% were applied for the experiment. Experiment was carried out by randomized block design with three replications. Table 3 shows amount of applied fertilizer for artemisia cultivation at the experiment site of the Saemangeum reclaimed land.

Plant height was measured by average of ten plants, and survival ratio was obtained by percent of the survived plant number to the transplanted 20 plants, biomass of weed and artemisia were harvested in the area of $1.8 \mathrm{~m}^{2}$ $(0.9 \times 2 \mathrm{~m})$ and then estimated by the area of $1000 \mathrm{~m}^{2}$ (10a) after air drying.

\section{Results and Discussion}

Soil salinity change. Knott (1962) reported that $4 \mathrm{dS}$ $\mathrm{m}^{-1}$ of ECe by saturation-paste extract method was classified as injury limit level of low salt tolerance crops (Knott, 1962). Lee et al. (2003) reported that regression equations between $\mathrm{ECe}$ and DF 1:5 were DF1:5=1.3624 $\ln (\mathrm{ECe})+5.1386\left(\mathrm{r}^{2}=0.37^{* * *}\right.$ for soils of more than $50 \%$ silt content and DF1:5=1.9505 $\ln (\mathrm{ECe})+5.3679\left(\mathrm{r}^{2}=0.66^{* * *}\right)$ for soils of less than $50 \%$ silt content. Therefore, $4 \mathrm{dS} \mathrm{m}^{-1}$ of ECe is equivalent to $8 \mathrm{dS} \mathrm{m}^{-1}$ of value measured by 1:5 dilution method, because silt content of the experiment soil is $23.2 \%$ in Table 1 . In this experiment, average surface soil salinities measured at $0-20 \mathrm{~cm}$ depth in more than 20 places in the site, were lower than $2 \mathrm{dS} \mathrm{m}^{-1}$. It is considered that $2 \mathrm{dS} \mathrm{m}^{-1}$ measured by 1:5 dilution method is significantly lower enough than $4 \mathrm{dS} \mathrm{m}^{-1}$ of ECe by saturation-paste extract method. This means that most of artemisia plants may not be suffered from salt injury during growing period. Fig. 2 . shows soil salinity changes during growing period of artemisia at the experiment site of the Saemangeum reclaimed tidal land.

However, it was convinced that soil salinities of some area in the experiment site were still higher than $10 \mathrm{dS}$ $\mathrm{m}^{-1}$ as shown Fig. 1. Figure 1. shows spatial soil salinity distribution map at July 8, 2010.

The area more than $10.0 \mathrm{dS} \mathrm{m}^{-1}$ arrived approximately at $15 \%$ of total experiment site and it was estimated that the plants transplanted on this area had been confidently suffered from salt injury, because $10.0 \mathrm{dS} \mathrm{m}^{-1}$ of 1:5 dilution method is equvalent to $11 \mathrm{dS} \mathrm{m}^{-1}$ of ECe by estimation equation (Lee et al., 2003). Especially, it was

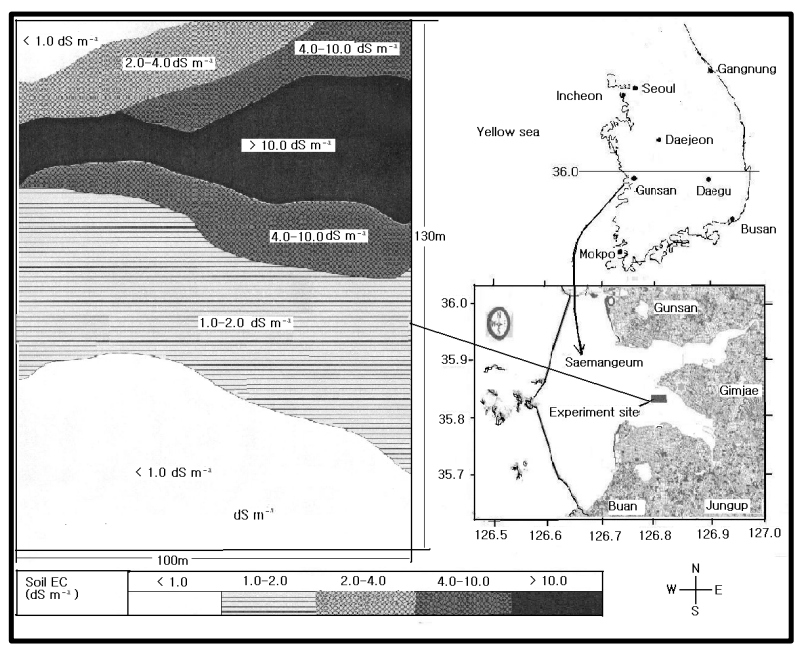

Fig. 1. Location of experimental site and spatial distribution map of surface soil EC measured in the experiment site at July 8, 2010. Soil EC was obtained by five times of multiplication from the values measured by the 1:5 dilution method.

Table 3. Amount of applied fertilizer for artemisia cultivation at the experimented site of the Saemangeum reclaimed land.

\begin{tabular}{|c|c|c|c|c|c|c|c|c|}
\hline \multicolumn{3}{|c|}{ Basal } & \multicolumn{2}{|c|}{ Additional } & \multicolumn{3}{|c|}{ Total } & \multirow{2}{*}{ Compost } \\
\hline $\mathrm{N}$ & $\mathrm{P}_{2} \mathrm{O}_{5}$ & $\mathrm{~K}_{2} \mathrm{O}$ & $\mathrm{N}$ & $\mathrm{K}_{2} \mathrm{O}$ & $\mathrm{N}$ & $\mathrm{P}_{2} \mathrm{O}_{5}$ & $\mathrm{~K}_{2} \mathrm{O}$ & \\
\hline \multicolumn{9}{|c|}{$\mathrm{kg} 10 \mathrm{a}^{-1}$} \\
\hline 12.6 & 4.2 & 7.2 & 4.0 & - & 16.6 & 4.2 & 7.2 & 600 \\
\hline
\end{tabular}


observed that soil EC was higher and plant growth was weaker in the lower area of micro-relief. This lower area was occasionally flooded for longer time by runoff water gathering from surrounding higher area. Sohn et al. (2009) reported that higher salinity of runoff water spilled out

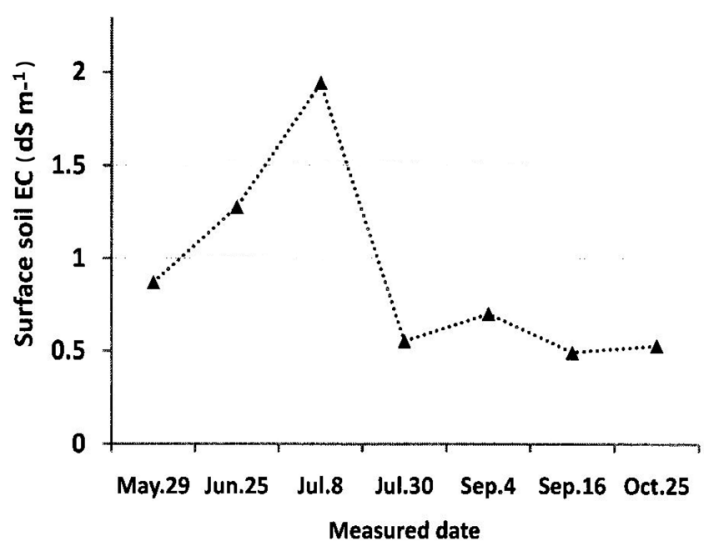

Fig. 2. Surface soil salinity changes during growing period of artemisia in the Saemangeum reclaimed tidal land. Soil EC was obtained by five times of multiplication from the values measured by the 1:5 dilution method.

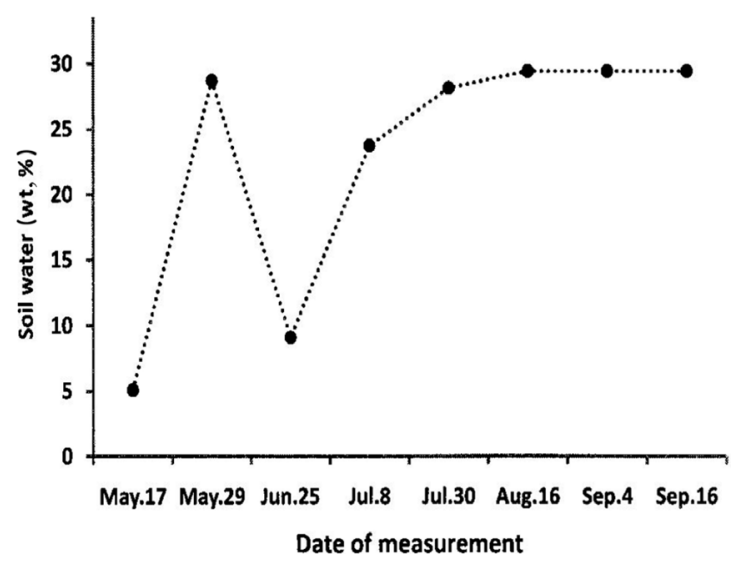

Fig. 3. Surface soil water changes during growing period of artemisia in the Saemangeum reclaimed tidal land. from cultivation ridge played a important role for soil salinity management and spatial difference. Therefore, it is estimated that spatial difference of soil EC could be from difference of desalting rate caused by micro-relief and others such as soil drainage or infiltration (Jung et al., 2002), bulk density (Yang et al.,2008).

Soil moisture change. Soil moisture is another important critical factor for plant growth. Fig. 3. shows soil water changes during the growing period of artemisia in the Saemangeum reclaimed tidal land.

Soil water contents maintained more than $20 \%$ during the growing period, except for around June 25, 2010. This means that artemisia was not suffered from drought injury, but might be fallen in wet injury risk because of higher moisture conditions of $25 \%$ more than field capacity by heavy rains during summer season of July-August, as shown in Table 4.

Sohn et al. (2010) reported that more than $25 \%$ of soil moisture might cause soil wetting by $21.6 \mathrm{~mm}$ of daily precipitation in the Saemangeum reclaimed tidal land. In fact, it was observed several times of field flooding in the experimental site. Soil wetting may resulted in reduction of photosynthesis and yield (Lee et al., 2010a; Park and Ha, 1984). Especially, it was observed that soil water content in the lower area of micro-relief was relatively higher than other area, because the lower area was intensively flooded by runoff water gathering from surrounding higher area and thick soil crust was formed by sediments eroded from ridges in this area. Soil surface crust generally results in formation of impeding layer reducing infiltration (Hillel, 1980). Therefore, it is estimated that spatial difference of soil water can be from micro-relief difference and others such as soil drainage difference by soil crust formation.

Table 4. Mean air temperature, sunshine hours and rainfall recorded at the Buan station of the Korea Meterological Administration near the Saemangeum reclaimed tidal land in 2010.

\begin{tabular}{cccccccccc}
\hline \multirow{2}{*}{ Month } & \multirow{2}{*}{ Mean air temp. } & Sunshine & Rainfall & Rainy & \multicolumn{5}{c}{ Days rained daily more than } \\
\cline { 7 - 10 } & & & & days & $30 \mathrm{~mm}$ & $50 \mathrm{~mm}$ & $80 \mathrm{~mm}$ & $662 \mathrm{~mm}$ \\
\hline & & & & & & & & & \\
May & 16.7 & 214.0 & 119.0 & 7 & 2 & 0 & 0 & 0 \\
Jun. & 21.9 & 188.3 & 21.8 & 12 & 0 & 0 & 0 & 0 \\
Jul. & 25.7 & 153.6 & 266.6 & 18 & 3 & 2 & 1 & 0 \\
Aug. & 27.2 & 147.0 & 362.6 & 19 & 5 & 1 & 0 & 0 \\
Sep. & 22.6 & 175.7 & 116.5 & 14 & 1 & 0 & 0 & 0 \\
Oct. & 14.3 & 184.8 & 32.3 & 7 & 0 & 0 & 0 & 0 \\
\hline
\end{tabular}


Relationship between plant growth and soil moisture or soil salinity. Soil moisture and soil salinity are the most critical factors for crop growth. In order to know the relationship between plant growth (plant height) and soil salinity or soil water content, statistical analysis for significance test of correlation coefficient and derivation of regression equation was carried out by using data measured at 8th of July, 2010, when the highest value of soil salinity was recorded during crop cultivation. Table 5 shows the relationship between plant growth and soil moisture or soil salinity measured in the Saemangeum reclaimed tidal land at the 8th of July, 2010.

It was calculated that plant growth was not significantly correlated with soil water content, but significantly correlated with surface soil salinity in the Saemangeum reclaimed tidal land. This means that soil salinity is more important factor to be controlled for summer crops than soil water in the reclaimed tidal land.

Correlation coefficient between plant height (y) and surface soil salinity (x) was statistically significant and regression equation was derived as $\mathrm{y}=-16.59 \ln (\mathrm{x})+43.852$, as shown in Fig. 4.

According to regression equation, plant height became theoretically zero at $14 \mathrm{dS} \mathrm{m}^{-1}$ although it was observed that real data showed zero at $12 \mathrm{dS} \mathrm{m}^{-1}$. According to estimation equation of Lee et al (2003), 12 and $14 \mathrm{dS} \mathrm{m}^{-1}$ measured by 1:5 dilution method are equivalent to more than $10 \mathrm{dS} \mathrm{m}^{-1}$ of ECe by saturation-paste extract method.

Correlation coefficient between survival ratio (y) and surface soil salinity $(\mathrm{x})$ was statistically significant and regression equation was derived as $\mathrm{y}=0.6453 \mathrm{x} 2-17.566 \mathrm{x}+$ 103.99, as shown in Fig. 5.

Survival ratio became theoretically zero at $8.7 \mathrm{dS} \mathrm{m}^{-1}$ in the regression equation. $8.7 \mathrm{dS} \mathrm{m}^{-1}$ measured by $1: 5$ dilution method is equivalent to $6 \mathrm{dS} \mathrm{m}^{-1}$ of ECe measured by saturation-paste extract method when the value is estimated by equation of Lee et al (2003). This means that survival ratio and plant growth of artemisia have been critically suffered from more than about $9 \mathrm{dS} \mathrm{m} \mathrm{m}^{-1}$ measured by 1:5 dilution method.
Effect of transplanting time on growth of artemisia. It is reported that weed occurrence is positively related with non-seeded area of planting row and is much more in the conventional row seeding than in drill seeding or broadcasting (Park, et al., 1986; Ha, et al., 1983). In the experiment site, planted area is relatively wide because of $90 \mathrm{~cm}$ interval in row and weed occurrence may be

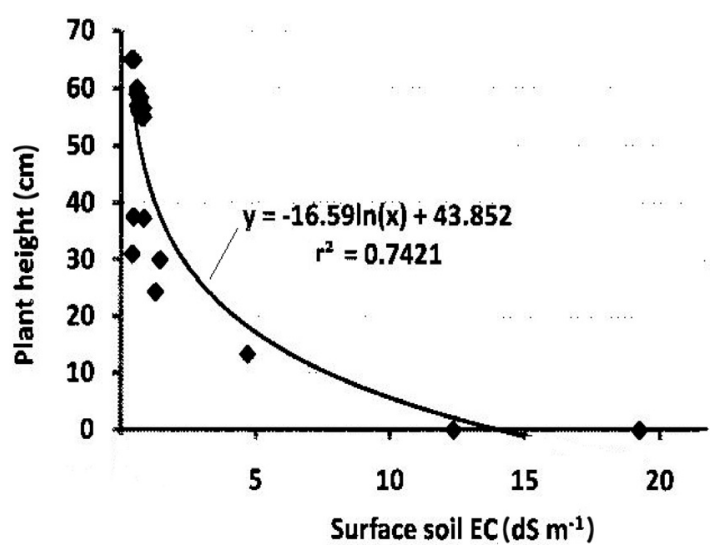

Fig. 4. Relationship between surface soil salinity and plant height of artemisia measured at the 8th of July in the Saemangeum reclaimed tidal land. Soil EC was obtained by five times of multiplication from the values measured by the 1:5 dilution method.

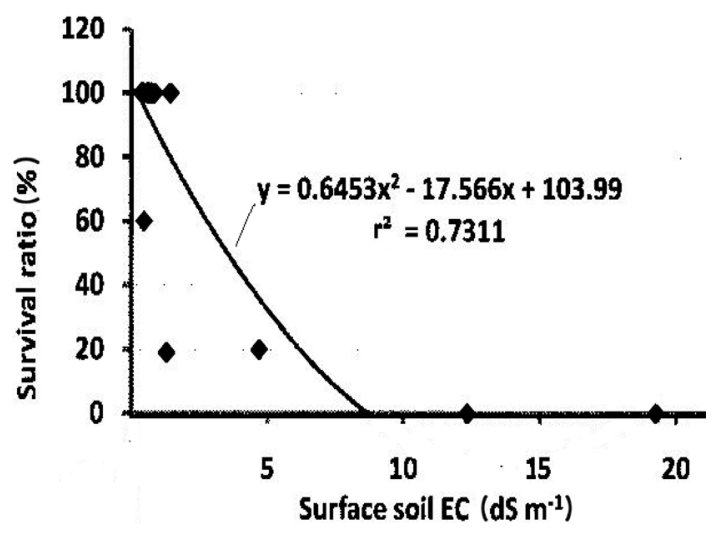

Fig. 5. Relationship between surface soil salinity and survival ratio of artemisia transplanted in the Saemangeum reclaimed tidal land. Soil EC was obtained by five times of multiplication from the values measured by the 1:5 dilution method.

Table 5. Significance test of comelation coefficients between plant growth (plant height) and soil water or surface soil salinity measured at the 8 th of July, 2010 when the highest value of soil salinity was recorded during crop cultivation.

\begin{tabular}{ccc}
\hline \hline Factor & Plant growth & Soil salinity \\
\hline Soil water & $-0.357^{\text {ns }}$ & $0.500^{\text {ns }}$ \\
Soil salinity & $-0.798^{* *}$ & 1 \\
\hline
\end{tabular}

${ }^{\mathrm{ns}}$ non-significance, $*$ significance at $\mathrm{p}=0.01$ and d.f. $=10$ 


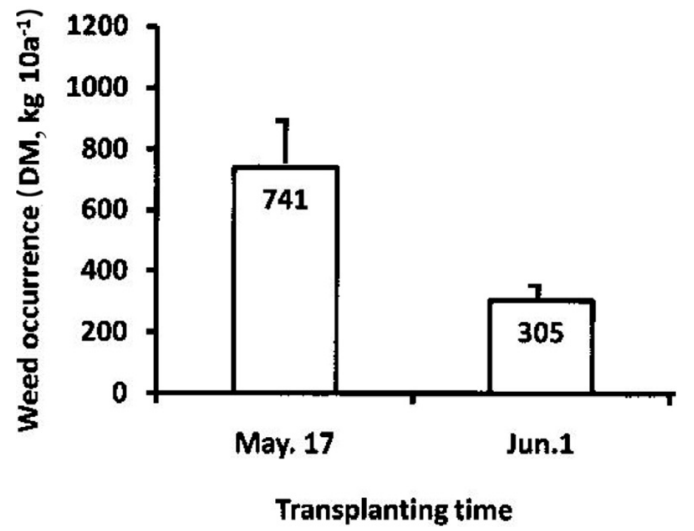

Fig. 6. Comparison of weed occurrence between nomal and late transplanting times of artemisia at the expenimental field in the Saemangeum reclaimed tidal land. The bars represent the standard deviation.
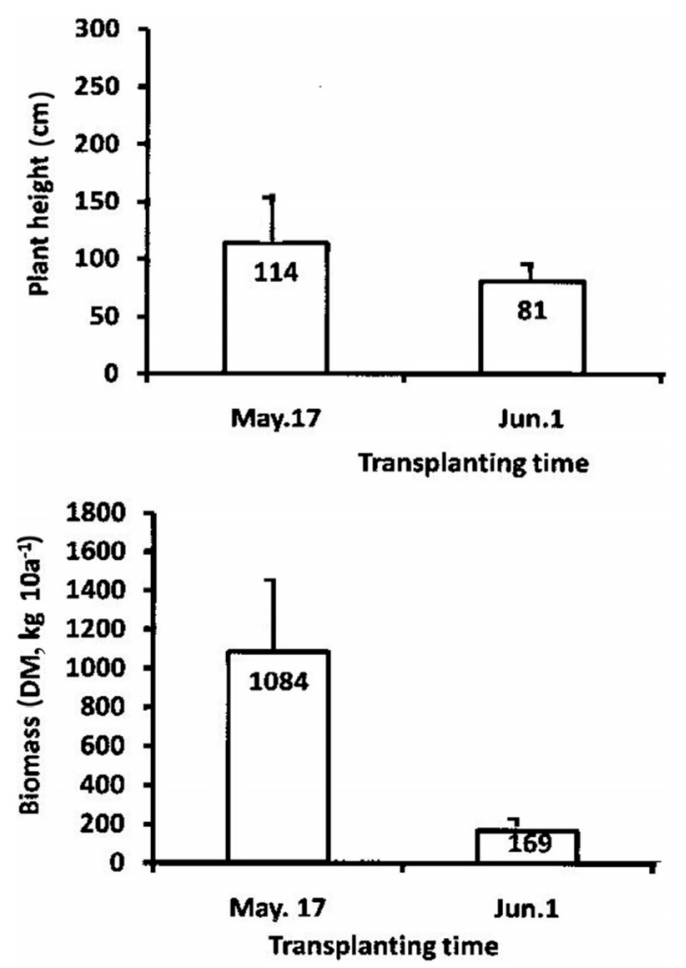

Fig. 7. Comparison of plant height and biomass production between normal and late transplanting times of artemisia at the experimental field in the Saemangeum reclaimed tidal land. The bars represent the standard deviation. much more unless good weed-control practice is done. Weed occurrence was also related with transplanting time. Figure 6. shows difference of weed occurrence according to transplanting time.

Although weed was manually controlled one time in the middle of July, weed occurrence at harvest season was 2.4 times more in the block transplanted at May 17 than the block done at June 1, 2010, This means that early transplanting may be resulted in higher weed occurrence than late transplanting and intensive weed control is more needed for good growth of plant in early transplanting than in late transplanting. Weed occurrence negatively influence for plant growth by worsening of cultural and biological environment, and finally result in yield reduction (Ryu and Kim, 2006).

Crop growth is very sensiable to seeding time, because climatological and cultural conditions are changeable to difference of season in the temperate regions. In this experiment, transplanting time was very effectively contributed to plant height growth and biomass production as well as weed occurrence, as shown in Fig. 7.

Plant height of artemisia was $114 \pm 21$ and $81 \pm 11 \mathrm{~cm}$ for transplanting at May 17 and that at June 1, respectively. Dry weight of individual artemisia plant was $244 \pm 194$ and $38 \pm 4 \mathrm{~g} \mathrm{plant}^{-1}$ and biomass (DM) was 1,084 \pm 382

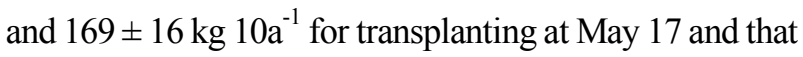
at June 1, respectively. Lee et al. (2010) reported that average height and dry weight of Korean artemisia were $179-225 \mathrm{~cm}$ and $136.5 \pm 10.0 \mathrm{~g}$, respectively. Therefore, plant height and dry weight were higher and heavier in the block transplanted at May 17, but were lower and lighter in the block transplanted at June 1 than those of previous research report (Lee et al., 2010). In this experimental result, biomass production was 6.4 times more in early transplanting than in late transplanting. This big difference of plant growth could be somewhat from less rainfall and shorter duration of sunshine in June (late transplanting) than May (early transplanting),

Table 6. Analysis of variance by randomized block design with three replications for the effect of transplanting time on biomass production of artemisia annua $L$. at the experimented site of the Saemangeum reclaimed tidal land.

\begin{tabular}{ccccc}
\hline \hline Factor & d.f & SS & MS & F-value \\
\hline Total & 5 & $1,695,947$ & & $1.15^{\mathrm{ns}}$ \\
Block & 2 & 155,497 & 77,749 & $18.52^{*}$ \\
Treatment & 1 & $1,256,752$ & $1,256,752$ & 67,849 \\
Error & 2 & 135,698 & & \\
\hline
\end{tabular}

${ }^{\mathrm{ns}}$ non-significance, $*$ significance at $\mathrm{p}=0.05$ 


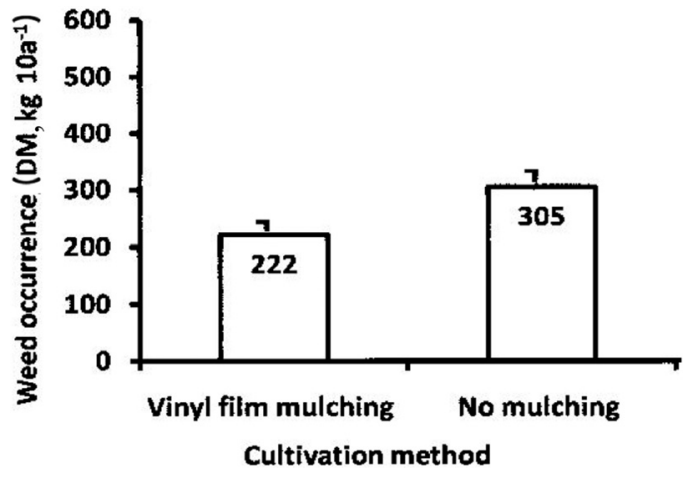

Fig. 8. Comparison of weed occurrence between vinyl-film mulching and no mulching cultivation of artemisia at the experimental field in the Saemangeum Reclaimed Tidal Land. The bars represent the standard deviation.
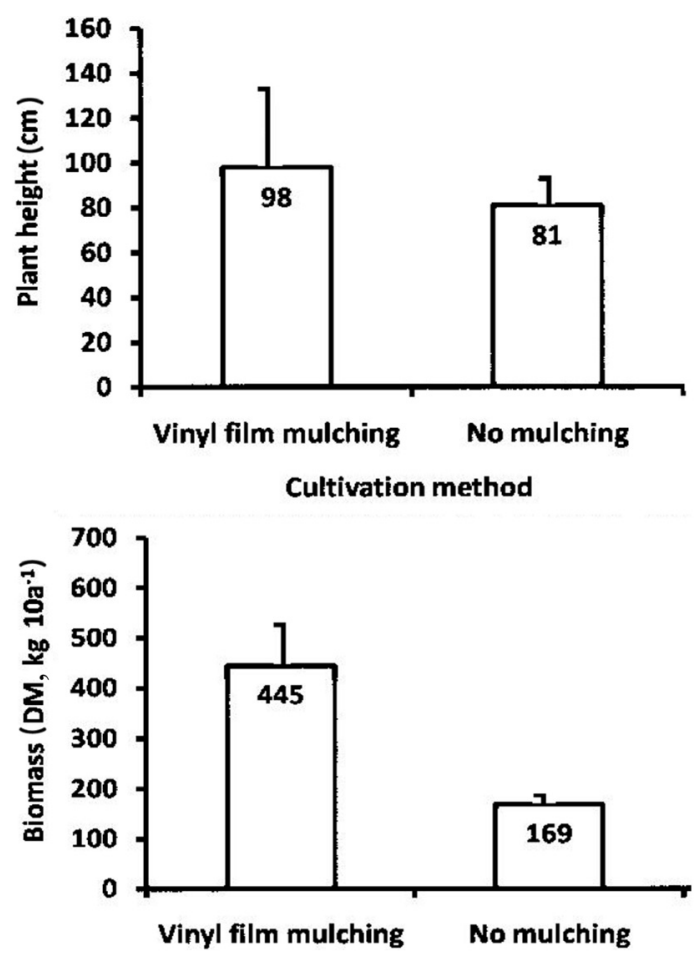

Fig. 9. Comparison of plant height and biomass production between vinyl-film mulching and no mulching cultivation of artemisia at the experimental field in the Saemangeum Reclaimed Tidal Land. The bars represent the standard deviation. as shown in Table 4. Importance of transplanting time was statistically proved in effective for biomass production, as shown in Table 6. Consequently, early transplanting is more beneficial for biomass production of artemisia than late transplanting.

Effect of vinyl mulching treatment on growth of artemisia. Generally, mulch is positively effective to crop growth because of benefits for weed control, reduction of evaporation and soil erosion, soil water conservation, soil temperature increase and others (Brady, 1990). Especially, increase of weed occurrence linearly decrease crop yield (Park et al.,1986). In this experiment, mulching of black vinyl-film was very effective to weed control, because $305 \pm 52 \mathrm{~kg} 10^{-1}$ of weed dry matter were occurred in the no-mulching while $222 \pm 34 \mathrm{~kg} 10^{-1}$ were done in the vinyl film mulching, as shown in Fig. 8.

In the experiment, vinyl-film mulching also contributed to plant height and biomass increase, as shown in Fig. 9.

However, amount of biomass produced in the vinylfilm mulching was not statistically different from the no-mulching treatment, although $445 \pm 163$ and $169 \pm 16$ $\mathrm{kg} 10 \mathrm{a}^{-1}$ of biomass was produced in the vinyl-film mulching and no-mulching, respectively. In order to know whether vinyl mulching treatment is statistically effective or not for biomass production, F-test was carried out by analysis of variance for randomized block design with three replications. Table 7 shows result of statistical analysis.

The reasons that amount of biomass had big standard deviation and mulching benefit for biomass production was not statistically proved, were considered to be from spatial difference of soil salinity and flooding caused by micro-relief difference and others, because they might interfered with crop growth. However, it is considered that vinyl-film mulching is useful for weed control and biomass production in the Saemangeum reclaimed tidal land.

Table 7. F-test by analysis of variance of randomized block design with three replications for the effect of vinyl film mulching treatment on biomass production of artemisia annua $L$. at the experimented site of the Saemangeum reclaimed tidal land.

\begin{tabular}{ccccc}
\hline Factor & d.f. & SS & MS & F-value \\
\hline Total & 5 & 167,107 & & $1.41^{\text {ns }}$ \\
Block & 2 & 31,159 & 15,580 & $10.38^{\text {ns }}$ \\
Treatment. & 1 & 113,988 & 113,988 & \\
Error & 2 & 21,961 & 10,980 & \\
\hline
\end{tabular}

\footnotetext{
${ }^{\mathrm{ns}}$ non-significance at $\mathrm{p}=0.05$
} 


\section{Conclusion}

The experiment was carried out to evaluate the effect of transplanting time and vinyl-film mulching treatment on the growth of artemisia in the Saemangeum reclaimed tidal land. Artemisia plants had been partly suffered from salt injury, because soil salinities in some area during growing period had been measured higher than $10 \mathrm{dS} \mathrm{m}^{-1}$. $10.0 \mathrm{dS} \mathrm{m}^{-1}$ of 1:5 dilution method is equivalent to $11 \mathrm{dS}$ $\mathrm{m}^{-1}$ of ECe by estimation equation (Lee et al., 2003) is more than $4 \mathrm{dS} \mathrm{m}^{-1}$ of ECe as injury limit level of low salt tolerance crops. Consequently, soil EC was significantly correlated with growth of plant height and survival ratio of transplanted plants, and then the regression equations between plant height $(\mathrm{y})$ and soil EC (x) and between survival ratio $(\mathrm{y})$ and soil $\mathrm{EC}(\mathrm{x})$ were expressed as $\mathrm{y}=-16.59 \ln (\mathrm{x})+43.852\left(\mathrm{r}^{2}=0.7421\right)$ and $\mathrm{y}=0.6453 \mathrm{x}^{2}-17.566 \mathrm{x}$ $+103.99\left(r^{2}=0.7311\right)$, respectively.

Early transplanting may be resulted in higher weed occurrence than late transplanting because weed occurrence was much more in the block transplanted at May 17 than the block done at June 1, 2010. In addition, early transplanting is more advantageous than late transplanting for biomass production and effectiveness of early transplanting was statistically proved in the Saemangeum reclaimed tidal land, because $1,084 \pm 382 \mathrm{~kg} 10 \mathrm{a}^{-1}$ of biomass were produced in the early transplanting, but only $169 \pm$ $16 \mathrm{~kg} 10 \mathrm{a}^{-1}$ were produced in the late transplanting.

Vinyl-film mulching also contributed to reduction of weed occurrence and increase of biomass production. However, mulching treatment was not statistically effected for biomass increase, although biomass was numerically increased by changing from $169 \pm 16 \mathrm{~kg}_{10 \mathrm{a}^{-1}}$ in the

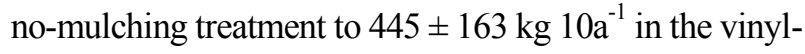
film mulching treatment. The reasons that amount of biomass had big standard deviation and mulching benefit for biomass production was not statistically proved, were from spatial difference of soil salinity and flooding by micro-relief and others, because they might interfered with crop growth.

In conclusion, early transplanting is more beneficial for biomass production of artemisia, and also vinyl-film mulching may be useful for reduction of weed occurrence and increase of plant growth and biomass production in the Saemangeum reclaimed tidal land.

\section{References}

Brady, N.C. 1990. The nature and properties of soils. 10th ed. pp 410-412. MacMillan Pub. Co., New York.

Cumming, J.N., P. Ploypradith, and G.H. Posner. 1997. Antimalarial activity of artemisinin (qinghaosu) and related trioxanes:mechanisms of action. Adv. Pharmacol.37:253-297.

David, J.C. 1973. Statistics and data analysis in geology. John Wiley \& Sons, Inc., New York.

Dondorp, A.M., F. Nosten, and P. Yi. 2009. Artemisinin resistance in Plasmodium falciparum malaria. N.Engl.J.Med. 361(5): 455-467.

Ha, Y.W., Y.I. Nam, M.E. Park, and C.H. Cho. 1983. Distribution of weed population in the winter wheat and barley field in Korea. Korean J.Weed Sci. 3:121-128.

Hillel, D. 1980. Fundamentals of soil physics. p216-217. Academic press, New York.

Hou, J., D. Wang, R. Zhang, and H. Wang. 2008. Experimental therapy of hepatoma with artemisinin and its derivatives: in vitro and in vivo activity, chemosensitization, and mechani는 of action. Clin Cancer Res 14(7):5519-5530.

Jansen, F.H. 2006. The herbal tea approach for artemesinin as a therapy for malaria. Trans R Soc.Trop.Med.Hyg. 100(3):285286.

Jung, J.L., S.J. Ryu, M.K. Oh, N.H. Baek, J.K. Koh, and J.G. Lee. 2002. Varietal responses of rice growth and yield to soil salt content. Korean J. Crop Sci. 47(6):422-426.

Jung, Y.S., S.H. Cho, J.E. Yang, J.J. Kim, and H.S. Lim. 2000. Available phosphorus and electrical conductivity of the saturated extracts of soils from the plastic film houses. Korean J. Soil Sci. Fert. 33(1):1-7.

Knott, J.E. 1962. Handbook for vegetable growers. p44-45. J.W. Willey \& Sons, Inc.

Koning Lee, O. 2007. Progress in malaria research. 1st ed. Nova Science pub. Inc.

Lee, J.E., H.S. Kim, Y.U. Kwon, G.H. Jung, C.K. Lee, H.T. Yun, and J.G. Kim. 2010a. Responses of photosynthetic characters to waterlogging in soybean. Korean J. Crop Sci. 55(2):111-118.

Lee, J.H., C.B. Park, C.G. Park, Y.D. Shon, and S.G. Moon. 2010b. Studies on major agronomic characteristics of Korean Artemisia annua L. Korean J. Medicinal Crop Sci.18:46-50.

Lee, S.H., B.D. Hong, Y. Ahn, and H.M. Ro. 2003. Estimation of conversion factors for electrical conductivities measured by saturation-paste and 1:5 water extraction. Korean J. Soil Sci. Fert. 36(4):193-199.

NAAS. 2000. Analysis of soil and plant. National Inst. of Agr. Sci. \& Teck. RDA, Suwon, Korea.

NICS. 2006. Illustrated book of autochthonous floras in the Saemangeum reclaimed land. The national Institute of Crop Science, RDA, Korea.

Noedl, H., Y. Se, K. Schaecher, B.L. Smith, D. Socheat, and M.M. Fukuda. 2008. Evidence of artemisinin-resistant malaria in western Cambodia. N. Engl.J.Med. 359(24):2619-2620.

Park M.E. and Y.W. Ha. 1984. Studies on grain filling in wheat and barley. III. Effect of flooding treatment in the maturing period of barley. Res.Rept. ORD 26-2(crop) 112-117. 
Park, M.E. and S.H. Yoo. 1989. Spatial variation analysis of soil characteristics and crop growth across the land partitioned boundary. I. Spatial variation of soil physical properties. Korean J. Soil Sci. Fert. 22(3):163-172.

Park, M.E., Y.H. Ryu, Y.W. Ha, and Y.I. Nam. 1986. Effect of cultural methods on yield and yield component of wheat and barley. Korean J. Crop Sci. 31:493-498.

RDA. 2007. Studies on friendly environmental development for foundation of multiple agriculture in reclaimed land. Rural Development Administrate.

RRI. 2006. Agricultural complex development for upland \& horticultural crops in the Saemangeum reclaimed farmland. Res. Rpt. Rural Research Institute. pp1-504. Korea Rural Community \& Agriculture Corporation.

Ryu, S.N. and G.S. Kim. 2006. Introduction to crop science. pp 249-252, 322. KNOU Press, Seoul, Korea.

Sohn, Y.M., G.Y. Jeon, J.D. Song, J.H. Lee, and M.E. Park. 2009. Effect of drip irrigation on soil salinity control and growth of cabbage at the newly reclaimed tidal lands in Korea. Korean J. Soil Sci. Fert. 42(6):492-499.

Sohn, Y.M., J.D. Song, G.Y. Jeon, D.H. Kim, and M.E. Park. 2010. Effect of soil salinity and culturing condition on the maintenance of ridge and the growth of upland crops in the Saemangeum reclaimed tidal land. Korean J. Soil Sci. Fert. 43(5):407-417.

White, N.J. 1997. Assessment of the pharmacodynamic properties of antimalarial drugs in vivo. Agents Chemother 41(7):14131422.

Yang, C.H., C.H.Yoo, J.H. Jung, B.S. Kim, W.K. Park, J.H. Ryu, T.K. Kim, J.D. Kim, S.J. Kim, and S.H. Baek. 2008. The change of physico-chemical properties of paddy soil in reclaimed tidal land. J. Korean Soc. Soil. Fert. 41(2):94-102.

Yoo, S.H. and M.E. Park. 2004. Proposal of land-use planing for agricultural use of the Saemangeum reclaimed land. J. Soc. Agr. Res. on Reclaimed Lands 2:68-91. 